\title{
O ENFRENTAMENTO DA CORRUPÇÃO NO MARANHÃO: O CASO DAS OPERAÇÕES ESPECIAIS DA CGU
}

\section{THE FIGHT AGAINST CORRUPTION IN MARANHÃO: THE CASE OF CGU SPECIAL OPERATIONS}

\author{
Welliton Resende Silva \\ Deuzilene Viégas \\ wresende189@gmail.com
}

\section{RESUMO}

Analisamos atuação da Controladoria Geral da União - CGU no Maranhão no enfrentamento à corrupção, com as Operações Especiais. Identificamos 23 Operações de 2007 a 2018. Isso mostra a corrupção presente nas gestões e evidencia também as ações de combate. Consideramos expressivos os resultados obtidos nesta investigação. Ponderamos que as Operações contribuíram para diminuição da impunidade.

PALAVRAS-CHAVE: corrupção, operações especiais, Maranhão, cidadania, accountability.

\begin{abstract}
We analyzed the performance of the Federal Comptroller General - CGU in Maranhão in the fight against corruption, with Special Operations. We identified 23 Operations from 2007 to 2018. This shows the corruption present in the management and also highlights the combat actions. We consider expressive the results obtained in this investigation. We believe that Operations contributed to the reduction of impunity.
\end{abstract}

KEYWORDS: corruption, Special operations, Maranhão, citizenship, accountability 


\section{INTRODUÇÃO}

O homem, em toda sua existência, procurou realizar atividades balizadas por controle, verificando que tudo ocorre conforme o plano adotado, as instruções recebidas e princípios estabelecidos (CHIAVENATO, 1993). O objetivo seria localizar fraquezas e erros, retificando-os e prevenindo recorrências. Por analogia, denota-se, que o meio mais favorável à proliferação da corrupção é aquele onde há falta de controle. Assim, o órgão que não dispõe de mecanismos eficientes de controle estará fadado a desvio de finalidade. Engana-se quem acredita que o ato de corromper está ligado apenas ao jogo político, partidário ou institucional. A lei de Gerson (levar vantagem em tudo) pode ser aplicada a qualquer cidadão que visa seus interesses próprios em detrimento do bem comum.

No que concerne à administração pública, o controle é a direção que um poder, órgão ou autoridade exerce sobre a conduta funcional de outro. No Brasil, qualquer atuação administrativa governamental está condicionada aos princípios expressos no art. 37 da Constituição Federal de 1988 que dispõe:

A administração pública direta e indireta de qualquer dos Poderes da União, dos Estados, do Distrito Federal e dos Municípios obedecerá aos princípios de legalidade, impessoalidade, moralidade, publicidade e eficiência e, também, ao seguinte (BRASIL, 1988):

Criada em 2003, a Controladoria Geral da União (CGU) centraliza o controle interno da Administração Pública Federal e desempenha papel de relevo no combate à corrupção. A agenda do enfrentamento ao mau uso do dinheiro público ganhou novos contornos com a eclosão das Operações Especiais realizadas em parceria com órgãos de controle e investigação da administração pública (internos e externos) que propiciou, entre outras, a troca de informações de inteligência

O presente artigo traça a trajetória histórica do enfrentamento à malversação dos recursos públicos no Maranhão, dando particular ênfase às Operações Especiais realizadas no período de 2007 a 2018 em prefeituras municipais, órgãos estaduais, Organizações NãoGovernamentais (ONG's). O texto organizado em três partes. A primeira seção apresenta as origens da corrupção e como esse fenômeno empobrece a sociedade. A segunda aborda a trajetória das Operações Especiais realizadas no Maranhão tendo como base o período supracitado. Ao final, é feita uma reflexão acerca do significado dessa experiência inovadora e seus impactos na administração pública nos três entes federativos. 


\section{AS ORIGENS DA CORRUPÇÃO}

O termo corrupção é definido nos dicionários como "ação ou efeito de corromper; decomposição, putrefação" ou "depravação, desmoralização, devassidão", ou como formas de "sedução e suborno". É um modo de conseguir algo de forma, proibida, contrária a lei, antiético ou imoral. Analisando o tema percebe-se que as referências a ele não são novas. Antes dos romanos, Platão já havia alertado que até mesmo o Estado ideal tende a se degenerar com o decorrer do tempo, pois tudo que nasce é passível de corrupção. Fernando Filgueiras (2006) discorrendo sobre a temática e sustenta que a corrupção em Roma, na visão de Cícero, encontrava-se ligada à falta de transparência nas decisões públicas e na desonestidade dos cônsules romanos.

Depreende-se, que a necessidade da sociedade ter controle dos recursos adquiridos pelo Estado e da forma com que estes são gastos, vêm de tempos antigos. Aristóteles (2009) argumenta que existem três formas de governo puras. A Monarquia onde o governo de um reina sobre os demais indivíduos. A Aristocracia enquanto governo de alguns sobre os demais e por fim o Governo Constitucional no qual a maioria governa para o bem de todos. $\mathrm{O}$ filósofo grego também observa as formas impuras de governo, que seriam os desvios das formas puras ocorrem quando determinada classe social toma o poder para si.

Quadro 1-As formas de governo segundo Aristóteles

\begin{tabular}{|c|c|}
\hline Formas de governo puras & Formas corrompidas \\
\hline Monarquia & Tirania \\
Aristocracia & Oligarquia \\
Governo Constitucional (Democracia) & Democracia (Demagogia) \\
\hline
\end{tabular}

Fonte: Elaboração própria

Em todos os casos, o movimento é um só: "a sobreposição das vantagens pessoais (desejos) à eudamonia (bem comum) tornando o governo corrompido" (FILGUERIAS, 2007, p. 6). Sob esta ótica (sob essa ética), a corrupção é o fracasso dos governos a partir da sobreposição das vantagens privadas sobre o bem comum.

Patrícia Aranovich (2007) destaca que em Maquiavel a corrupção pode ser compreendida como desarmonia entre a forma e a matéria do corpo político onde, ainda que a república seja melhor que a monarquia, a monarquia não corrupta pode ser melhor que a 
república corrompida. O monarca virtuoso poderia conduzir a fortuna do povo ao bom governo, enquanto governantes republicanos não teriam a mesma sorte, se corrompidos.

No século XIX o sociólogo alemão Max Weber (1864-1920), desenvolveu o conceito de patrimonialismo. Derivado das palavras patrimônio e patrimonial pode ser definido como concepção de poder onde esfera pública e privada confundem-se. Um líder político é qualificado como patrimonialista quando, ao assumir um cargo na esfera pública usa a estrutura estatal para satisfazer suas necessidades pessoais, privadas.

No Brasil, o patrimonialismo foi estudado por vários pensadores, no entanto, aquele que mais se ateve às definições sociológicas de Weber e procurou aplicá-las à realidade histórica brasileira foi Raymundo Faoro, cuja obra "Os Donos do Poder - Formação do Patronato Político Brasileiro" (1958) tornou-se uma referência. Faoro e outros autores procuram explicar as raízes históricas, sobretudo herdadas de Portugal, que conformam o patrimonialismo no Brasil.

Desde a formação dos primeiros clãs rurais de colonos no século XVI, em terras brasileiras, os domínios privados (latifúndios) formavam também um núcleo de ação política. Grande parte da autoridade local nas vastas províncias do território era administrada e policiada por milícias vinculadas aos senhores de terras (semelhante ao que ocorria no sistema feudal). O poder local personalista teve grande influência na formação do Brasil resistindo em algumas regiões, à centralização política do Estado e à impessoalidade que este exige. Um dos fenômenos mais explicitamente patrimonialistas da história política brasileira foi $o$ coronelismo durante a República Velha. O “coronel”, típico líder paternalista que, ocupando o cargo de governador ou de prefeito transformava seu domínio de atuação política em extensão de sua casa ou fazenda.

No século XIX o filósofo alemão Karl Marx, em “A Luta de Classes na França (1848 -1850)", alertava que a corrupção endêmica é filha dos gastos estatais descontrolados. Constatava que esta empobrecia o Estado, transferindo para as dinastias econômica, financeira e política riquezas geradas pela corrupção. Marx advertia que "suborno", "corrupção", "malversação" e "ladroeiras", não pode ser programa de governo. Para o notável pensador, combater a corrupção está acima de ideologias. Em sua teoria defende que a corrupção estatal é uma inimiga dos trabalhadores que deve ser combatida em todas as frentes.

Conforme Boito Junior

o Estado capitalista estabelece a distinção formal entre recursos públicos e privados e a ideia de corrupção origina-se de tal distinção é apenas relativa 
ao formal, pois na prática, os recursos do Estado estão a serviço do capitalismo. (BOITO JR, 2002, p. 90)

$\mathrm{O}$ autor aduz, que, na prática também os recursos públicos alimentam o sistema capitalista. Embora o discurso seja de que os apenas os recursos privados são apropriados pelos donos dos meios de produção. Ainda segundo o autor, isso se dá de modo que tanto a prática da corrupção quanto sua condenação, seja retórica ou real, devem ser tratadas como ideologia. Ou seja, como uma representação inconsciente, deformada e interessada sobre a natureza e o funcionamento do Estado capitalista, deixando transparecer que o Estado atende aos interesses de todos.

Décio Saes assevera que "a ideia da corrupção é parte integrante e fundamental da ideologia burguesa, mais precisamente da ideologia burguesa do Estado" (SAES, 1998, p. 211). Para fundamentar sua concepção afirma que desde a organização dos Estados précapitalistas (Mundo Antigo e Europa feudal), havia norma que estabelecia o monopólio dos cargos estatais pela classe dominante, nesse contexto os recursos materiais e financeiros desses Estados não se separavam dos recursos materiais e financeiros dos indivíduos ocupantes desses cargos. Ou seja, os ocupantes dos cargos estatais geriam os recursos públicos emaranhados com os privados.

Na literatura recente há autores que defendem a corrupção. Nye (1967), avalia os "custos e benefícios" do impacto da corrupção sobre os governos, e observa alguns ganhos. Afirma que a corrupção pode produzir desenvolvimento econômico, integração nacional e capacidade governamental, embora reconheça também que produz desperdício de recursos e que possa gerar instabilidade política e perda de capacidade governamental. Na concepção de Nye um bom governo e de bem comum, corrupção e bons governos podem se retroalimentar.

Diferentes autores têm diferentes concepções sobre bem comum, corrupção, bom governo e ética. Este fato expressa que os termos em questão variam de acordo com a interpretação dos autores, um dado povo, território e contexto histórico. É verossímil que a corrupção é um problema crônico e seu surgimento está intimamente relacionado à criação das primeiras civilizações. Porém, é fato que essa prática foi intensificada após o surgimento do capitalismo, sistema econômico que proporciona maiores desigualdades sociais e fortalece a ideia de quanto mais se acumula riqueza melhor.

Para Boris Fausto (2001), no Brasil, a corrupção começa quando funcionários da Coroa Portuguesa faziam "vista grossa" aos produtos naturais, o pau-brasil, por exemplo, 
comercializados de forma ilegal. No período escravista brasileiro (1530 a 1888), que perdurou mesmo após a proibição do comércio de negros pela Lei Eusébio de Queiroz (1850), a entrada de africanos escravos continuou acobertada por senhores de terras. Paradoxalmente, em 1888, com a abolição da escravatura, o comércio de escravos persistiu, através de subornos e propinas. Em suma, a corrupção esteve na gênese do povo brasileiro da colonização à Nova República, apesar do advento da instituição de um complexo aparato jurídico e de instituições no âmbito do Estado.

\subsection{A corrupção como fator de empobrecimento da sociedade maranhense}

No Maranhão, a primeira referência ao tema corrupção foi proferida pelo Padre Antonio Vieira em 1654, em seu célebre "Sermão aos peixes". Por meio de sátira Vieira, em sua pregação, denunciou a disputa entre os colonizadores portugueses que estavam no Brasil e os moradores locais.

Para Mário Meirelles (1970) no período colonial a vida no Maranhão era precária e miserável. Para o autor as principais razões eram a ambiência pontuada por "lutas mesquinhas”, predomínio da corrupção, suborno até assassinatos. Afirma ainda que uma das razões para a Revolta de Beckamn (1684) foi o fato de o governador do Maranhão à época, Francisco de Sá de Meneses, ser um homem de índole reprovável, e agindo de maneira contrária aos interesses dos colonos.

O jornalista Ed Wilson (2014), em artigo intitulado “Água na Política de Ana Jansen à Ricardo Murad”, a pré-História do abastecimento de água em São Luís é contada em fatos e lendas. Uma das mais conhecidas diz respeito à poderosa Ana Jansen (1787-1869), detentora do monopólio da água no século XIX. Jansen vendia água em carroças puxadas a burro, um lucrativo negócio tocado por um exército de escravos que transportavam o líquido pelas ruas de São Luís. Por volta de 1850, o governo da Província autorizou a criação da Companhia de Águas do Rio Anil. Jansen, famosa pelas perversidades contra os adversários, teria mandado colocar gatos mortos e apodrecidos nos depósitos da Companhia, espalhando a notícia da contaminação na água do concorrente. Segundo Wilson essa sabotagem funcionou e a empresa concorrente faliu. Sob as auspicias de tal episódio, teria nascido doravante a concorrência desleal no Maranhão. 
A corrupção definida como meio de burlar os mecanismos de controle, dentro da administração pública, apresenta nuanças que diferem em muito, das práticas adotadas pelo setor privado como, por exemplo, no caso retratado de Ana Jansen. A consequência destas práticas é o alto custo social, pois na medida em que investimentos são inibidos, a capacidade de geração de receitas pelo Estado diminui, e do pouco arrecadado, o que não é mal investido sofre desvios na sua aplicação. Por conta dessa lógica perversa, o Maranhão possui o maior número de pessoas vivendo em situação de pobreza, segundo revela a Síntese de Indicadores Sociais (SIS), divulgada pelo Instituto Brasileiro de Geografia e Estatística (IBGE, 2019).

Os dados alarmantes apontam que cerca de 54,1\% dos maranhenses vivem com menos de R\$ 406 por mês. Ainda segundo o IBGE, mais de 81\% dos maranhenses não possui saneamento básico adequado, a média nacional é de 35,9\%. Além disso, 32,7\% das pessoas não teem acesso à coleta direta ou indireta de lixo e para 29,2\% não há abastecimento de água. Os dados atestam ainda que cerca de $3 \%$ da população vive sem nenhum tipo de renda no Maranhão, quando a média nacional é de $2,4 \%$.

Consideramos que a corrupção produz ineficiência e injustiça, cujos efeitos produzem reflexos sobre a legitimidade política do Estado. De qualquer modo que se apresente é um fenômeno que enfraquece a democracia, a confiança no Estado, a legitimidade dos governos e a moral pública.

A atuação da CGU no Maranhão no enfrentamento à corrupção por meio das Operações Especiais representa-se como um capítulo à parte na história do combate à corrupção nas administrações públicas municipais e estadual. Assim como nas transferências diretamente relacionadas à ONG's e outras entidades. Utilizando-se de troca de informações de inteligência com órgãos como a Polícia Federal, o Ministério Público Federal, Ministério Público Estadual, Tribunal de Contas do Estado e Tribunal de Contas da União a CGU consegue sobressair-se em ações importantes de combate a corrupção. Destarte, o tema Operações Especiais é o objeto de estudo no próximo capítulo tendo como recorte àquelas ocorridas no Maranhão.

\section{A CGU E O ENFRENTAMENTO À CORRUPÇÃO NO MARANHÃO}

A CGU, órgão integrante da burocracia governamental central, inicialmente constituída como instrumento de controle interno, assumiu papel de destaque no enfrentamento da corrupção no Brasil e, notadamente, no Estado do Maranhão. Nesse sentido, as Ações Investigativas da CGU consistem em trabalhos especiais, por meio de 
processos, procedimentos e instrumentos específicos como inspeção in loco, por exemplo, que propiciam uma atuação com enfoque ainda mais forte no efetivo combate à corrupção.

De acordo com a página online da CGU, o Governo Federal estabeleceu um padrão inédito de cooperação entre instituições relacionadas com a defesa do Estado Brasileiro. Respeitadas as identidades de cada órgão, CGU, Polícia Federal (PF), Ministério Público Estadual (MPE), Ministério Público Federal (MPF), Tribunal de Contas da União (TCU), Conselho de Controle de Atividades Financeiras (COAF), entre outros, atuam em parceria para o controle do dinheiro público e o enfrentamento da corrupção.

Na CGU, essas ações são executadas em três frentes distintas de trabalho: Demandas Externas, Auditorias Especiais e Operações Especiais (CGU, 2010). Por demandas externas entendem-se denúncias, requisições e pedidos de informação encaminhados à CGU por órgãos como a PF, o MPF, o COAF entre outros. As Auditorias Especiais, por seu turno, são solicitações oriundas dentro do próprio Governo Federal ou por decisão da própria CGU, baseadas em denúncias. E, por derradeiro, as Operações Especiais são parcerias realizadas com outros órgãos para combater a corrupção e a má aplicação na gestão dos recursos públicos federais em todo o país. No período de 2007 a 2018, a CGU realizou as seguintes Operações Especiais no Estado do Maranhão:

Quadro 2 - Operações Especiais da CGU (1997-1999)

\begin{tabular}{|c|c|c|l|}
\hline Operação & Ano & Parceria & \multicolumn{1}{c|}{ Municípios } \\
\hline Rapina I & 2007 & PPF & $\begin{array}{l}\text { Axixá, Araióses, Paulo Ramos, Governador } \\
\text { Newton Bello, Nina Rodrigues, São Luís } \\
\text { Gonzaga, Tufilândia, Tuntum Urbano Santos }\end{array}$ \\
\hline Nêmesis & 2008 & PF e MPF & São Luís. \\
\hline Rapina II & 2008 & PPF & $\begin{array}{l}\text { Alcântara, Cândido Mendes, Carutapera, } \\
\text { Centro Novo, Marajá do Sena, Olho D'Água } \\
\text { das Cunhãs, São Roberto, Magalhães de } \\
\text { Almeida, Paraibano e Viana. }\end{array}$ \\
\hline Orthoptera & 2009 & PPF & Alcântara. \\
\hline Rapina III & 2009 & PPF e MPF & São Luís. \\
\hline Rapina IV & 2009 & MPF e & $\begin{array}{l}\text { Imperatriz, São Luís, Governador Edson } \\
\text { Lobão, Montes Altos e São Pedro de Água } \\
\text { Branca. }\end{array}$ \\
\hline
\end{tabular}

Fonte: Elaboração própria, a partir de levantamentos na página da CGU 
Operações Especiais no Maranhão iniciaram em 2007 com a realização da Operação Rapina que desbaratou ação de quadrilha formada por 51 empresas e outras 40 que davam suporte a desvios de recursos públicos, mediante o uso de notas fiscais falsas e licitações forjadas envolvendo varias prefeituras municipais. No total, 104 pessoas foram presas, sendo 86 no Maranhão e 18 no Piauí. Dentre os presos estavam o ex-presidente da Federação dos Municípios do Estado do Maranhão, Cleomar Tema, a prefeita de Axixá, Sonia Campos (DEM), a prefeita de Nina Rodrigues, Yara Quaresma.

O prejuízo financeiro potencial foi estimado em R $\$ 30.605 .593,32$, de um montante fiscalizado de R\$ 62.245.413,88. Convém ressaltar que com a apreensão de documentos em escritórios de contabilidade nas buscas e apreensões para cumprir mandados da Rapina I, a CGU encontrou fraudes em prestações de contas que apontavam que outras prefeituras também se utilizavam do mesmo modus operandi. Os documentos apreendidos lastrearam a realização das Operações II, III e IV e a Operação Orthoptera, que apurou fraudes nas movimentações financeiras da conta do FEB/FUNDEB no município de Alcântara.

Em 2008 foi deflagrada a Operação Nêmesis, em conjunto com a PF e o MPF, para cercear ação de quadrilha composta por servidores federais do Núcleo Especial do Ministério da Saúde-NEMS especializada no desvio de valores dos Suprimentos de Fundos obtidos mediante fraude ao Sistema Integrado de Administração Financeira - SIAFI. Estima-se que o grupo tenha desviado dos cofres públicos federais mais de $\mathrm{R} \$ 500$ mil, podendo alcançar a quantia de R 1,5 milhão se levado em consideração os valores de diárias que também eram fraudadas.

Quadro 3 - Operações Especiais (2010-2012)

\begin{tabular}{|l|l|l|l|}
\hline Operação & Ano & Parceria & Municípios \\
\hline Orthoptera II & 2010 & & São Francisco do Brejão \\
\hline Rapina V & 2010 & PPF e MPF & Alcântara e São Pedro da Água Branca. \\
\hline Rapina VI & 2010 & PPF & Satubinha \\
\hline Donatário & 2011 & PPF e MPF & São Luís \\
\hline Usura & 22011 & PPF & São João do Paraíso \\
\hline Alien & 22012 & PF e MPF & Paço do Lumiar \\
\hline
\end{tabular}

Fonte: Elaboração própria, a partir de levantamentos na página da CGU.

Em 2010, em parceria com a PF, foi deflagrada Operação “Orthoptera II”. O objetivo era desarticular quadrilha especializada em desviar verbas federais. A operação teve o apoio 
da Superintendência de Polícia Federal no Piauí, da Procuradoria da República no Maranhão e do MPE/MA. O Objetivo foi cumprir 11 mandados de busca expedidos pela Justiça Eleitoral do município de Barão do Grajaú/MA a partir de monitoramento da utilização excessiva de movimentações financeiras à conta do Fundeb, mediante cheques avulsos, saques contra recibo e cheques nominais ao emitente, bem como o uso "contas de passagem", dentre outras manobras, cuja finalidade era maquiar o desvio de verbas oriundas da Educação. A operação apurou que o ex-prefeito de São Francisco do Maranhão, Jônatas Alves de Almeida, comandava o esquema. As análises realizadas pela CGU apontaram prejuízos potenciais da ordem de R 2,4 milhões.

Também no biênio 2010-2012, foram realizadas mais duas Operações Rapinas. A primeira em função da detecção que o montante $\mathrm{R}$ \$ 2.720.471,92 (dois milhões, setecentos e vinte mil, quatrocentos e setenta e um reais e noventa e dois centavos) foi sacado direto na "boca do caixa" de contas de 12 Programas Federais por meio de saques contra recibo ou cheques avulsos, no período de seis meses (setembro/2009 a fevereiro/2010). A segunda para prender em flagrante o prefeito do município de Satubinha, localizado a $272 \mathrm{~km}$ da capital, que também havia sacado dinheiro das contas da prefeitura ilegalmente. Ressalte-se que foi acusado de fraudar 23 processos licitatório sutilizando-se de duas empresas de fachada.

Os dados colhidos em dois Inquéritos Civis instaurados em 2009 pela $1^{\text {a }}$ Promotoria de Justiça da Comarca de Porto Franco e apensados a Relatório de Fiscalização da CGU subsidiaram as investigações que culminaram na Operação Usura (2011). O trabalho resultou na prisão do secretário de Infraestutura de Imperatriz à época, Roberto Vasconcelos, dos exprefeitos e prefeito de São João do Paraíso, José Aldo e Raimundo Galdino, respectivamente. O desvio de recursos públicos federais repassados à Prefeitura de São João do Paraíso, localizado à755 Km da capital, acarretou prejuízo de R\$ 5,57 milhões aos cofres públicos. Vinte e quatro empresas estavam envolvidas no esquema desvendado pela CGU, PF e MPE.

Uma ação desenfreada de organização criminosa especializada em fraudar licitações e desviar verbas públicas no município de Paço do Lumiar, Região Metropolitana da Capital, gerou a Operação Alien. Dentre as principais constatações identificadas destacaram-se a falsificação de documentos e assinaturas, montagem de processos licitatórios e direcionamento do resultado dos procedimentos licitatórios. Tais fatos resultaram em prejuízo potencial da ordem de R 6 milhões (78 \% do montante analisado). A Operação cumpriu 39 mandados judiciais. 
A Operação Donatário 2009 visou coibir ação de quadrilha no desvio de recursos públicos federais, modalidade de Crédito Instalação, liberados pelo Instituto Nacional de Colonização e Reforma Agrária - INCRA, para construção de casas em projetos de assentamentos (PA), em favor de beneficiários do Programa Nacional de Reforma Agrária. A operação deu cumprimento a 39 mandados de busca e apreensão expedidos pela Justiça Federal no Maranhão. Foi identificada a participação no esquema cerca de 55 pessoas, entre: servidores e ex-servidores do INCRA, Instituto de Colonização e Terras do Maranhão, um policial civil do Maranhão, construtores, lobistas e presidentes de associações de assentados.

Quadro 4 - Operações Especiais (2013-2015)

\begin{tabular}{|l|l|l|l|}
\hline Operação & Ano & Parceria & Municípios \\
\hline $\begin{array}{l}\text { Cheque } \\
\text { Branco }\end{array}$ & 2013 & PPF & $\begin{array}{l}\text { São Luís, Serrano do Maranhão, Paulo Ramos, } \\
\text { Turilândia, Santa Luzia, Pedro do Rosário, } \\
\text { Cajapió, Arari. }\end{array}$ \\
\hline Usura II & 2013 & PPF & Bacabal e Zé Doca. \\
\hline Geist & 2014 & GMPE e PF & Anajatuba \\
\hline Attalea & 2015 & $\begin{array}{l}\text { MPE, MPF } \\
\text { e PF }\end{array}$ & Anajatuba \\
\hline $\begin{array}{l}\text { Sermão aos } \\
\text { peixes }\end{array}$ & 2015 & PPF e MPF & São Luís \\
\hline
\end{tabular}

Fonte: Elaboração própria, a partir de levantamentos na página da CGU

A Operação Cheque Branco (2013) apurou esquemas de agiotagem envolvendo gestores e ex-gestores municipais e empresários, especialmente do ramo de factoring, por meio do desvio de recursos federais, notadamente destinados à educação e à saúde. $\mathrm{O}$ modus operandi consistia em receber dos gestores municipais cheques e guias de saques, vinculados às contas abertas de recursos federais dos municípios, todos assinados "em branco", como forma de pagar empréstimos pessoais contraídos a juros exorbitantes, deixando ao alvitre dos agiotas os recursos públicos federais repassados aos municípios. Foram cumpridos 10 mandados de condução coercitiva.

A Operação Usura II (2013) teve início com afastamento judicial do sigilo bancário de três contas movimentadas por um agiota que possibilitou a análise de uma amostra de operações financeiras realizadas em três contas. Os desvios foram estimados em 7,5 milhões na área da Saúde de Bacabal (MA), e 4,5 milhões na área da Saúde e Educação (FUNDEB) do município de Zé Doca (MA). A operação contou com a participação de 11 auditores da CGU no cumprimento de 19 mandados de busca e apreensão. 
Operação Geist (2014) realizada em parceria com o Grupo Especial de Combate ao Crime Organizado (Gaeco) do MPE e PF desarticulou um esquema de fraudes com recursos do Fundeb por meio de licitações fraudulenta na Prefeitura de Anajatuba. A organização criminosa desviava recursos públicos nas áreas de transporte, censo, alimentação e reforma escolar, em especial em recursos do Fundeb, para favorecimento de agentes públicos, suas partes relacionadas e terceiras pessoas físicas e jurídicas.

A Operação Attalea (2015) prendeu o então prefeito de Anajatuba, Helder Aragão, e outros sete envolvidos. A quadrilha, segundo apurou a CGU e a PF, chegou a desviar mais de R\$ 15 milhões do Fundeb. Ao todo foram cumpridos 11 mandados judiciais, sendo oito de prisão, uma condução coercitiva, além de três medidas cautelares.

A Operação Sermão aos peixes (2015) mudou o foco da atuação da CGU, da PF e do MPF para o Governo do Estado do Maranhão e cumpriu 13 mandados de prisão preventiva, 60 mandados de busca e apreensão e 27 mandados de condução coercitiva, entre eles a do exsecretário Estadual de Saúde do Maranhão, Ricardo Murad. As investigações tiveram início em 2010, quando o então Secretário de Saúde, se utilizou do modelo de 'terceirização' da gestão da rede de saúde pública estadual. Segundo a investigação, ao passar a atividade para entes privados - seja em forma de Organização Social (OS) ou Organização de Sociedade Civil de Interesse Público (Oscip) - o então secretário tentou fugir dos controles da lei de licitação, empregou pessoas sem concurso público e contratou empresas sem licitação e com isso facilitou o desvio de verba pública federal, com fim específico de enriquecimento ilícito dos envolvidos.

No período de investigação, os fluxos de recursos destinados pela União, por meio do Ministério da Saúde, ao Fundo Estadual de Saúde do Maranhão era um montante de R\$ 2 bilhões. Os investigados estão respondendo pelos crimes de estelionato, associação criminosa e peculato (Art. 171, 288 e Art. 312 do Código Penal), bem como por organização criminosa

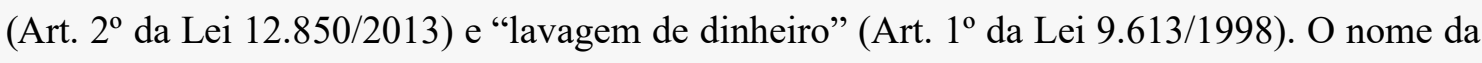
operação é alusivo ao sermão do Padre Antônio Vieira que, em 1654, falou sobre como a terra estava corrupta, censurando seus colonos com severidade.

Quadro 5 - Operações Especiais (2016-2018)

\begin{tabular}{|l|l|l|l|}
\hline Operação & Ano & Parceria & Municípios \\
\hline Cooperari & 2016 & $\begin{array}{l}\text { MPE e } \\
\text { PF }\end{array}$ & São José de Ribamar, São Luis e Paço do Lumiar. \\
\hline
\end{tabular}




\begin{tabular}{|l|l|l|l|}
\hline Voadores & 2016 & PPF & $\begin{array}{l}\text { São Luís, Imperatriz, Araguaína Palmas/TO e } \\
\text { Arenópolis/TO. }\end{array}$ \\
\hline Abscôndito & 2016 & PPF & $\begin{array}{l}\text { São Luís, Imperatriz, Araguaína, Palmas/TO e } \\
\text { Arenópolis/TO. }\end{array}$ \\
\hline Pegadores & 2017 & PPF & São Luís, Imperatriz, Amarante e Teresina/PI. \\
\hline Rêmora & 2017 & PPF & $\begin{array}{l}\text { Carutapera, Barreirinhas, Paulino Neves, Barra do } \\
\text { Corda, Imperatriz e Chapadinha }\end{array}$ \\
\hline $\begin{array}{l}\text { Operação } \\
\text { Torrentes } \\
\begin{array}{l}\text { II- Círculo } \\
\text { de Fogo }\end{array}\end{array}$ & 2018 & PF e MI & $\begin{array}{l}\text { Recife (PE), Jaboatão dos Guararapes (PE) e São } \\
\text { Luís (MA). }\end{array}$ \\
\hline
\end{tabular}

Fonte: Elaboração própria, a partir de levantamentos na página da CGU

A Operação Cooperari (2016) realizada em parceria com o GAECO do MPE e teve como objetivo desarticular organização criminosa acusada de desviar recursos públicos da área de educação, especificamente do FUNDEB, por meio de cooperativas contratadas por prefeituras de municípios maranhenses para prestarem serviços de transporte, limpeza, vigilância e outros serviços. A investigação apurou que a COOPMAR, apesar de contar com menos de três anos de constituição, obteve o maior volume de recursos contratados por prefeituras do Estado do Maranhão, envolvendo 11 municípios e quase R\$ 150 milhões em contratos. Foram cumpridos 14 mandados de busca e apreensão em residências e empresas. Foram bloqueadas contas de 15 pessoas físicas e jurídicas, além do sequestro e indisponibilidade de 8 imóveis e 11 veículos dos envolvidos. A operação contou, além dos servidores da CGU, com a participação de policiais civis, Promotores de Justiça e servidores do Ministério Público do Estado do Maranhão.

As operações seguintes Voadores (2016), Abscôndito (2016), Rêmora (2017) e Pegadores (2017) foram desdobramentos da Operação Sermão aos Peixes. A Voadores teve como objetivo apurar desvio de cerca de R\$ 36 milhões de reais através do desconto de cheques e posterior depósito nas contas de pessoas físicas e jurídicas. incluindo o saque de contas de hospitais. Os envolvidos estão sendo indiciados pelos crimes de embaraço à investigação de infração penal que envolva organização criminosa, peculato e lavagem de capitais. A Abscôndito, por sua vez, objetivou combater grupo criminoso que agia no sentido de destruir e ocultar provas, após possível vazamento da Operação Sermão aos Peixe. 
A Rêmora foi deflagrada para apurar prejuízo ao erário da ordem de R $\$ 18$ milhões. As investigações apontaram que os recursos destinados à OSCIP Instituto de Desenvolvimento e Apoio à Cidadania (Idac) que firmou contratos de gestão com a Secretaria de Saúde do Maranhão (SES/MA) para a administração de diversas unidades hospitalares estaduais, segundo apurou a investigação foram desviados por meio de vultosos saques em espécie. Após firmar os contratos de gestão com a aludida Secretaria, o Idac passou a receber centenas de milhares de reais dos cofres públicos, os quais deveriam ser empregados, com exclusividade, na administração de diversas unidades hospitalares estaduais.

A Pegadores foi destinada a apurar desvio de verbas federais provenientes do Fundo Nacional de Saúde que estaria ocorrendo por meio de fraudes na contratação e pagamento de pessoal no curso dos Contratos de Gestão e Termos de Parceria firmados com entidades do denominado terceiro setor, no período de 2013 a 2017. Em que pese a mudança de gestão no governo do Maranhão, os crimes continuaram ocorrendo na administração das unidades hospitalares do estado depois de 2015. Foram cumpridos 28 mandados de busca e apreensão, 17 mandados de prisão temporária, foi decretado afastamento da função pública do Superintendente de Acompanhamento à Rede de Serviços da SES/MA, quebra do sigilo bancário e fiscal de 8 envolvidos e bloqueio de ativos financeiros de pessoas físicas e jurídicas no montante aproximado de $\mathrm{R} \$ 91.366 .000,00$.

Por derradeiro, a Operação Torrentes II - Círculo de Fogo (2018) foi realizada em parceria com a PF/PE para desarticular organização criminosa, formada por empresários e agentes públicos, acusados de desviar recursos do Ministério da Integração Nacional (MI) destinados à assistência às vítimas da estiagem no estado do estado. A investigação, desdobramento da Operação Torrentes, deflagrada em novembro de 2017, ocorrida em Pernambuco, constatou que agentes do Corpo de Bombeiros Militar do Maranhão receberam vantagens indevidas para favorecer a contratação, em 2013, da mesma empresa fraudulenta, para fornecimento de cestas básicas e entrega de filtros de propileno para água em municípios do estado atingidos por forte seca naquele ano.

Os contratos investigados, cujos valores transferidos pelo MI superam R\$ 10 milhões, ocorreram a partir de adesão às atas de registro de preços elaboradas pela Casa Militar de Pernambuco. A Operação Torrentes II - Círculo de Fogo cumpriu sete mandados de prisão preventiva e nove mandados de busca e apreensão, nas cidades de Recife (PE), Jaboatão dos Guararapes (PE) e São Luís (MA). 


\section{CONSIDERAÇÕES FINAIS:}

Com base no exposto conclui-se que a corrupção, enquanto forma de desviar o Estado da função de prover o bem comum em detrimento de interesses particulares. Ao se analisar as Operações Especiais realizadas pela CGU, constatou-se que o órgão realizou um total 23 no período de 2007 a 2018, uma média de 2,09 por ano. Verificou-se que o maior número de ações foi para enfrentar a corrupção em municípios, em um percentual de $60,8 \%$ do total das OE's realizadas. Em geral tiveram por objeto derrotar o desvio de recursos públicos que ocorriam em prefeituras. Em seguida vem o Governo Estadual com 26,3\% para estancar a sangria nos cofres públicos na área da saúde. O Governo Federal, por sua vez, ficou com $8,6 \%$ e as ONG's que recebem recursos federais com $4,3 \%$.

Em linhas gerais, desde a realização da Operação Rapina I, em dezembro de 2007, as Operações Especiais realizadas no Maranhão representam 7\% das ações nacionais, se considerarmos o total de 337 operações (até agosto de 2018). O montante do prejuízo apurado em ações investigativas no estado foi de R\$ 296.122.612,01, de um total de R\$ 4.928.777.217,99, conforme dados da página oficial da CGU.

Convém salientar que a maior parte das Operações Especiais foi realizada com o intuito de coibir fraudes em licitações públicas. As mais comuns foram: sobre preço, sobre faturamento, desvios (não execução do objeto), irregularidades graves no processo licitatório (tais como conluio e montagem de processo licitatório, contratação direta com evidências de direcionamento, beneficiamento entre outras falhas graves) e ausência de prestação de contas. Denotando, por conseguinte, que do valor total fiscalizado, as políticas públicas das áreas de educação, saúde e infraestrutura foram as campeãs em desvio de dinheiro público. Nesse tocante, salta aos olhos as Operações Especiais realizadas para coibir o desvio de recursos públicos na Secretaria Estadual de Saúde- SES, o que sinaliza a fragilidade dos controles internos da gestão estadual.

O que se constata com o presente trabalho é que ação repressiva tem elevado a consciência crítica da intolerância ao fenômeno da corrupção. A realização das Operações Especiais abriu uma nova agenda de enfrentamento à corrupção na Administração Pública no Maranhão. O caso da CGU é expressivo dessa nova realidade, pois ela não atua mais apenas como controladora, mas também como ativadora das energias inteorganizacional congregando, cada vez mais, atores governamentais e sociais a se somarem a este esforço. Ademais, avaliamos que a realização das Operações Especiais contribuiu de modo significativo para diminuir da sensação de impunidade que, via de regra, acompanha os 
corruptos e corruptores. Outro fator importante é que as ações possibilitam à sociedade tomar conhecimento dos atos ilegais e eticamente reprováveis praticados por seus gestores.

\section{REFERÊNCIAS}

Brasil. Constituição da República Federativa do Brasil: texto constitucional promulgado em 5 de outubro de 1988, com as alterações determinadas pelas Emendas Constitucionais de Revisão nos 1 a 6/94, pelas EC nos 1/92 a 91/2016 e pelo Decreto Legislativo no 186/2008. Brasília: Senado Federal, Coordenação de Edições Técnicas, 2016. Disponível em: ttps://www2.senado.leg.br/bdsf/bitstream/handle/id/518231/CF88_Livro_EC91_2016.pdf?seq uence $=1$. Acesso em 05/10/2020.

BOITO JR, Armando. Política Neoliberal e Sindicalismo no Brasil. $2^{\text {a }}$ Ed. São Paulo: Xamã. 2002.

FILGUEIRAS, F. A corrupção do estado:perspectivas teóricas e seu processo social.Utopia y práxis latino-americana,Maracaíbo,v. 11, n. 34, p. 11-34, 2006.

NYE, Joseph. "Corruption and political development: a cost-benefit analysis," American Political Science Review, nº 61, 1957, pp. 417-427.

SAES, Decio. O Impacto da Teoria Althussseriana da Historia na Vida Intelectual Brasileira. In: Moraes, J Q. (org.) História do Marxismo no Brasil. V. III. Campinas: Unicamp. 1998.

WILSON. Ed. Água na Política. Disponível em <http://blogdoedwilson.blogspot.com/2014/03/agua-na-politica-de-ana-jansenricardo.html\#.XMw9gWe2rR80> Acessado em: 03 mai.2020. 